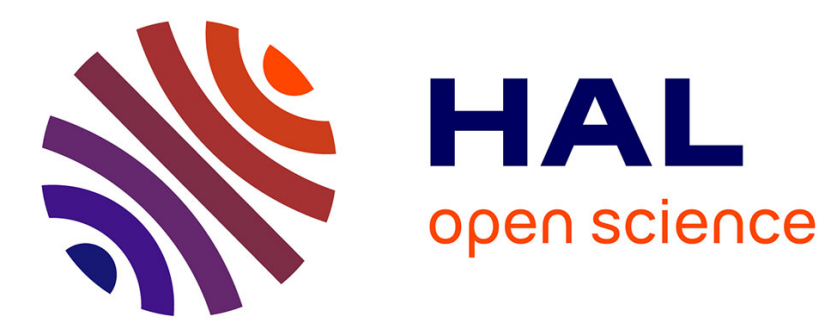

\title{
Selective hydrogenolysis of benzyl ethers in the presence of benzylidene acetals with Raney nickel
}

Aurélie Vincent, Joëlle Prunet

\section{To cite this version:}

Aurélie Vincent, Joëlle Prunet. Selective hydrogenolysis of benzyl ethers in the presence of benzylidene acetals with Raney nickel. Tetrahedron Letters, 2006, 47, pp.4075. 10.1016/j.tetlet.2006.03.189 . hal00087139

\section{HAL Id: hal-00087139 \\ https://hal.science/hal-00087139}

Submitted on 21 Jul 2006

HAL is a multi-disciplinary open access archive for the deposit and dissemination of scientific research documents, whether they are published or not. The documents may come from teaching and research institutions in France or abroad, or from public or private research centers.
L'archive ouverte pluridisciplinaire HAL, est destinée au dépôt et à la diffusion de documents scientifiques de niveau recherche, publiés ou non, émanant des établissements d'enseignement et de recherche français ou étrangers, des laboratoires publics ou privés. 


\title{
Selective hydrogenolysis of benzyl ethers in the presence of benzylidene acetals with Raney nickel
}

\author{
Aurélie Vincent and Joëlle Prunet ${ }^{*}$ \\ Laboratoire de Synthèse Organique,UMR CNRS 7652, Ecole Polytechnique, DCSO, F-91128 Palaiseau, France
}

\begin{abstract}
A simple method to remove selectively a benzyl group protecting a hydroxyl function in the presence of a benzylidene acetal by catalytic hydrogenolysis with Raney nickel is reported. This method was successfully applied to the synthesis of the C1-C14 fragment of dolabelides. (C) 2006 Elsevier Science. All rights reserved
\end{abstract}

Benzylidene acetals are frequently used as 1,2- and 1,3-diol protecting groups. They can be conveniently removed under neutral conditions by hydrogenolysis, or by acid hydrolysis. However, discrimination among reactive sites of the same class of benzyl-type protecting group is required for the synthesis of complex natural products. Indeed, in the course of our studies toward the synthesis of dolabelides, we needed to deprotect selectively the benzyl group at $\mathrm{C} 14$ in the presence of a para-methoxybenzyl (PMB) ether at $\mathrm{C} 3$ and the benzylidene acetal protecting the diol at $\mathrm{C} 9$ and $\mathrm{C} 11$ (Figure 1).

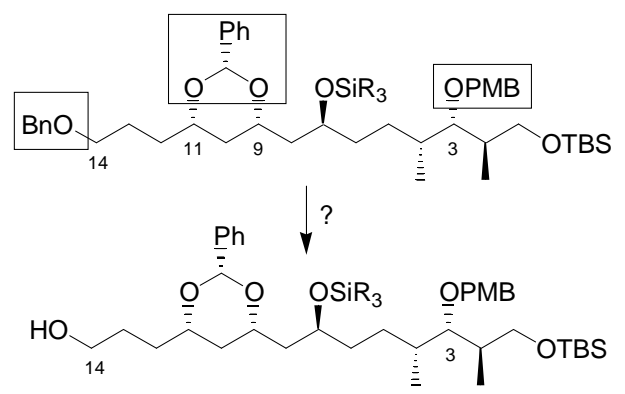

Figure 1. Selective deprotection of the $\mathrm{C} 1-\mathrm{C} 14$ fragment of dolabelides.

Catalytic hydrogenolysis offers the mildest method for deprotecting benzyl ethers. Moreover, the electronic properties of the aromatic ring introduce sufficient latitude in the rate of hydrogenolysis of benzyl ether protecting groups to allow selective deprotection. For example, selective hydrogenolysis of a secondary benzyl ether in the presence of a primary para-methoxybenzyl (PMB) ether is feasible using Raney Nickel in ethanol. ${ }^{1,2,3}$ However, when Tatsuta et al. used this method during their synthesis of herbimycin A, they observed the concomitant deprotection of a 4,5-disubstituted 1,3-benzylidene acetal. ${ }^{4}$ Indeed, only a few cases of selective removal of benzyl groups in the presence of 1,3-benzylidene acetals have been reported, and only for carbohydrate derivatives. Three of these methods involve transfer hydrogenation catalyzed by palladium or palladium hydroxide on carbon with cyclohexene, ${ }^{5}$ ammonium formate ${ }^{6}$ or hydrazine hydrate. ${ }^{7}$ The last one involves oxidation of the benzyl ether with tetrabutylammonium peroxydisulfate, followed by debenzoylation with sodium methoxide. ${ }^{8}$

In this paper, we describe the selective deprotection of benzyl ethers in some representative compounds in the presence of other benzyl-type protecting groups by hydrogenolysis with Raney nickel. ${ }^{9}$

We first examined the case of a simple monosubstituted 1,3-benzylidene acetal. No selective deprotection of even a primary benzyl group was possible (Table 1, entry 1). Fortunately, primary and even secondary benzyl ethers can be selectively deprotected in the presence of 4,6disubstituted 1,3-benzylidene acetals (entries 2 and 3). As expected, a PMB ether was stable under these conditions (entry 4). Application of this method to the C1-C14 fragment of dolabelide was successful as we managed to deprotect the benzyl group at $\mathrm{C} 14$ without hydrogenolysis of the PMB group or the benzylidene acetal (entry 5). However, the selectivity was not total for this substrate

\footnotetext{
* Corresponding author. Tel.: +3316933 48 73; fax: +33 1693338 51; e-mail: joelle.prunet@polytechnique.fr
} 
when a less bulky protecting group was present on the alcohol at C7: a 6:3:1 mixture of debenzylated product/starting material/triol was obtained with the TES derivative.

With 1,2-benzylidene acetals, no selective deprotection of benzyl groups was possible, even with a disubstitued acetal (entries 6 and 8). Interestingly, monoreduction of the 1,2-benzylidene acetal occurred very cleanly without deprotection of the benzyl group when carrying out the experiment at $0{ }^{\circ} \mathrm{C}$ (entry 7 ).

On the other hand, we also showed that a 1,3-dithiane or a conjugated ester can be selectively hydrogenated with Raney nickel in the presence of a primary benzyl ether (entries 9 and 10).

Table 1. Cleavage of benzyl ethers by catalytic hydrogenation using Raney nickel in ethanol.

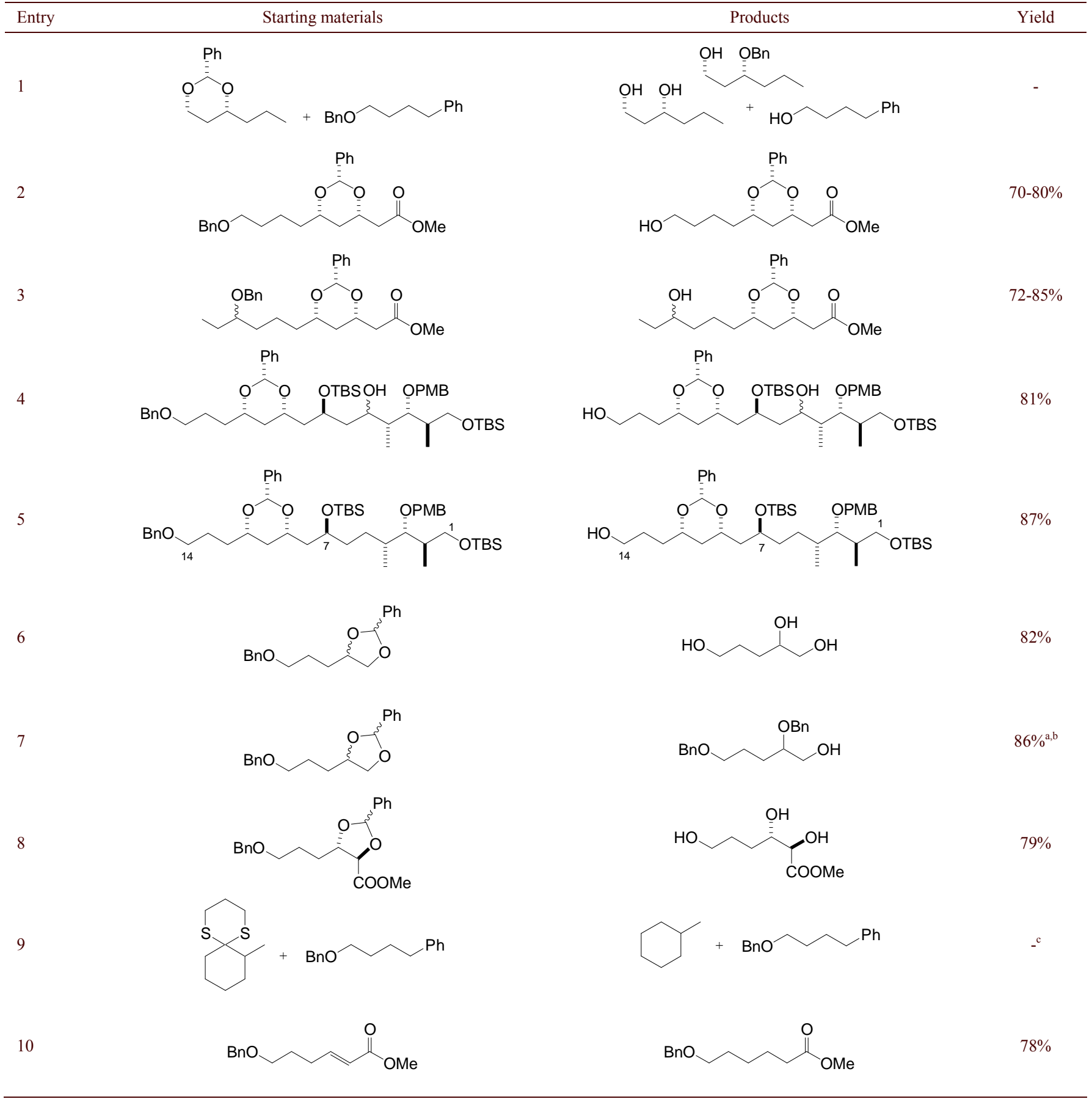


${ }^{\text {a }}$ Reaction carried out at $0{ }^{\circ} \mathrm{C}$; ${ }^{\text {b }}$ yield based on $25 \%$ recovered starting material; ${ }^{\mathrm{c}}$ quantitative recovery of the benzyl ether.

In conclusion, we have investigated the hydrogenation of $O$-benzyl ether protecting groups in the presence of diverse functional groups by catalytic hydrogenolysis with Raney Nickel in ethanol.

\section{Acknowledgements}

Financial support was provided by the CNRS and the Ecole Polytechnique. A. V. acknowledges the Délégation Générale pour l'Armement (DGA) for a fellowship.

\section{References}

1. Oikawa, Y.; Tanaka, T.; Horita, K.; Yonemitsu, O. Tetrahedron Lett. 1984, 25, 5397-5400.

2. Horita, K.; Yoshioka, T.; Tanaka, T.; Oikawa, Y.; Yonemitsu, O. Tetrahedron 1986, 42, 3021-3028.
3. Yoshino, T.; Nagata, Y.; Itoh, E.; Hashimoto, M. ; Katoh, T.; Terashima, S. Tetrahedron 1997, 53, 10239-10252.

4. Nakata, M.; Osumi, T.; Ueno, A.; Kimura, T.; Tamai, T.; Tatsuta, K. Tetrahedron Lett. 1991, 32, 6015-6018.

5. Hanessian, S.; Liak, T. J.; Vanasse, B. Synthesis 1981, 396397.

6. Bieg, T.; Szeja, W. Synthesis 1985, 76-77.

7. Bieg, T.; Szeja, W. Synthesis 1986, 317-318.

8. Chen, F.-E.; Peng, Z.-Z.; Fu, H.; Meng, G.; Cheng, Y.; Lü, Y.-X. Synlett 2000, 5, 627-628.

9. General procedure for hydrogenolysis of Bn groups over Raney Ni catalyst: a solution of a Bn ether in absolute EtOH $(0.1 \mathrm{M})$ was stirred under a hydrogen atmosphere (1 bar) over excess Raney Ni (Fluka, used as received) at $20^{\circ} \mathrm{C}$. After the reaction was complete, the catalyst was removed by filtration and the filtrate concentrated in vacuo. The residue was purified by chromatography on silica gel to give the corresponding product. 